\title{
The outcome of pregnancy in women suffering from migraine
}

\author{
Gillian WainscotT \\ M.B., Ch.B., D.C.H. \\ G. N. Volans $\dagger$ \\ B.Sc., M.R.C.P.
}

\author{
F. M. Sullivan* \\ B.Sc.(Hons.) \\ MARCIA WILKINSON \\ M.A., F.R.C.P.
}

The Princess Margaret Migraine Clinic, 22 Charterhouse Square, London, EC1M 6DX

\section{Summary}

The reproductive histories of 777 women suffering from migraine were compared with 182 non-migrainous women. The incidence of miscarriage, stillbirth and toxaemia of pregnancy was very similar in both groups and there was no increase in the number of congenital malformations in the children born to women who suffered from migraine compared with the control group or with the national average. It was concluded that women suffering from migraine did not have an increased risk of giving birth to children with deformity and it was unlikely that drugs most commonly used in the treatment of migraine were teratogenic.

\section{Introduction}

Ergotamine tartrate is widely used by migraine patients and a large proportion (c. 70\%) of migraine sufferers are women of child-bearing age (Wainscott, 1975). Although it is reported that $80 \%$ of women notice an improvement in their migraine during pregnancy (Freedman and Meritt, 1959), it is said by some to worsen during the early stages (Callaghan, 1968) and so the taking of ergotamine during the very early stages of pregnancy remains a probability. The authors felt it was important to determine whether the use of ergotamine for the treatment of migraine might be associated with an increased risk of congenital malformations. In the first instance it was decided to perform a retrospective survey of patients attending a migraine clinic to see whether there was a higher incidence of miscarriage or of malformations in the offspring. If an increased incidence was detected it would then be necessary to investigate further the drug history for clues to the aetiology. This technique has proved successful in

Correspondence: Dr G. Wainscott, Medical Adviser, Beecham Pharmaceuticals, Beecham House, Brentford, Middlesex.

* Present address: Senior Lecturer, Dept. of Pharmacology, Guy's Hospital Medical School, London, SE1.

$\dagger$ Present address: Deputy Director, Poisons Unit, Guy's Hospital, London, SE1. detecting an increase in malformation in epilepic patients (Annengers and Hauser, 1974).

\section{Methods}

The survey was carried out at the Princess Morgaret Migraine Clinic, London, between May 1973 and June 1974, except for four weeks when the doctor in charge was on holiday.

\section{Patients}

All new referrals to the Clinic, both femaleoand male, were asked to complete a questionnaire on migraine. The only patients excluded were domiciled outside the United Kingdom or unable to understand or speak English sufficien fy well to complete the questionnaire. Two groups कf women were selected:

(1) A migraine group - all new female patients who completed the questionnaire.

(2) A control group - the wives of all new, marriod male patients who completed the questionnaire.

\section{Questionnaire}

The questionnaire contained a variety of questions relating to the symptoms and possible causes $\overline{9}$ f migraine, the analysis of which is to be presented elsewhere. Amongst these questions was one sectian headed 'Association of migraine with disorders of pregnancy'. In this the patients were asked how many times they had been pregnant, how many children they had, whether any pregnancies had ended In miscarriage and at what stage of pregnancy this had occurred. There were also questions relating to the incidence of toxaemia, stillbirth and subsequemt death of children. There was a detailed question on birth defects which was as follows: 'A birth defects an abnormal condition which has been present from birth although perhaps not recognized until later life. There are minor defects such as a missing :or extra nipple, or webbed fingers or toes. There afe also more severe defects such as "hare-lip" or "hole-in-the-heart" or an abnormal limb. Have yoßr 
children any birth defects at all? If so, please give details for each child with a birth defect'.

The drug history was asked in relation to treatment for and between attacks of migraine. Any changes in this during each pregnancy were to be recorded.

\section{Procedure}

The questionnaires were handed by the receptionist to all suitable new patients who were requested to complete it whilst awaiting their consultation. After filling in the questionnaire the patient handed it to the doctor during the consultation when the answers were checked and clarified where necessary. The detailed drug history was then taken by the doctor.

In the case of male patients whose wives were not accompanying them, the questionnaire relating to pregnancy was taken home by the patient together with a reply-paid envelope. The returned questionnaires were checked by the doctor in charge and any ambiguities were resolved by writing to the wife or by questioning the husband on his next visit to the Clinic.

\section{Results}

Of 1115 questionnaires handed out, a total of $1096(98 \cdot 3 \%)$ were completed satisfactorily. 777 out of $790(98.3 \%)$ female patients returned completed questionnaires whilst of 319 male patients given the whole questionnaire, 210 were married and from these, 182 replies $(86.7 \%)$ were received. One of these was excluded from the analysis as the wife also had migraine, so that a total of 181 replies $(86.2 \%)$ were used to act as a control population.

The age distribution of the groups is shown in Table 1, and is remarkably similar in both and indicates that the variabilities due to difficulty in recall, etc. are likely to be the same in both groups.

The number of women who have been pregnant in the migrainous group and in the control group is shown in Table 2, together with the number in each group who suffered miscarriage, stillbirth or toxaemia. It is clear that the incidence of miscarriages,
TABle 1. Age distribution of female migraine patients and control group

\begin{tabular}{ccc}
\hline $\begin{array}{c}\text { Age group } \\
\text { (years) }\end{array}$ & $\begin{array}{c}\text { Female } \\
\text { migraine patients } \\
(\%)\end{array}$ & $\begin{array}{c}\text { Wives of male } \\
\text { migraine patients } \\
(\%)\end{array}$ \\
\hline $15-24$ & $149(19 \cdot 18)$ & $14(7 \cdot 74)$ \\
$25-34$ & $180(23 \cdot 17)$ & $56(30 \cdot 94)$ \\
$35-44$ & $181(23 \cdot 29)$ & $46(25 \cdot 41)$ \\
$45-54$ & $183(23 \cdot 55)$ & $42(23 \cdot 20)$ \\
$55-64$ & $74(9 \cdot 52)$ & $21(11 \cdot 60)$ \\
$65-74$ & $9(1 \cdot 16)$ & $2(1.11)$ \\
$75-84$ & $1(0 \cdot 13)$ & 0 \\
\hline
\end{tabular}

stillbirths and toxaemia is very similar in each group. The percentage of women who have been pregnant in the migraine group $(58 \%)$ is less than in the control group $(75 \%)(P<0.001)$ but this is probably because all of the controls are married whereas the marital status of the study group is not determined.

However, in women who have been pregnant at any time, there is no difference in the number of pregnancies per patient in the study group (2.54) compared with the control group (2.51). The outcome of individual pregnancies is shown in Table 3 . The percentage of pregnancies ending in miscarriage is equal in both groups as is the percentage occurring in the first trimester. The slightly larger percentage of pregnancies therapeutically terminated in the migraine group compared with the control group is not statistically significant $(P=0.09)$. It should be noted that this question was not specifically asked and detected only when discrepancies between the reported number of live-births were checked by the doctor. Since this was not done for the control group, as these women were not interviewed personally, these figures for the controls may be under-reported. However, the overall incidence was low and it was felt that a separate investigation was not justified.

\section{Congenital malformations}

The incidence of reported birth defects is shown in Table 4 and the actual defects listed in Table 5. In

TABLE 2. Number of women who have been pregnant in the migrainous group and in the control group, with the numbers suffering miscarriage, stillbirth or toxaemia

\begin{tabular}{|c|c|c|}
\hline & $\begin{array}{c}\text { Female } \\
\text { migraine } \\
\text { patients }\end{array}$ & $\begin{array}{l}\text { Wives of } \\
\text { male migraine } \\
\text { patients }\end{array}$ \\
\hline Total number of questionnaires handed out (or returned) & 777 & 181 \\
\hline $\begin{array}{l}\text { Number of women who have been pregnant } \\
\text { Number who have not been pregnant } \\
\text { Number of unresolved queries }\end{array}$ & $\begin{array}{l}450(57 \cdot 9 \%) \\
312 \\
15\end{array}$ & $\begin{array}{l}136(75 \%) \\
41 \\
4\end{array}$ \\
\hline Number of women who suffered miscarriage or stillbirth during one or more pregnancies & $121(27 \%)$ & $39(29 \%)$ \\
\hline Number of women who suffered toxaemia during one or more pregnancies & $82(18 \%)$ & $24(18 \%)$ \\
\hline
\end{tabular}


TABLE 3. Total number of pregnancies in migrainous women and in control group with the numbers of miscarriages, stillbirth and instances of toxaemia reported

\begin{tabular}{|c|c|c|}
\hline & $\begin{array}{l}\text { Female } \\
\text { migraine patients } \\
(n=450)\end{array}$ & $\begin{array}{l}\text { Wives of male } \\
\text { migraine patients } \\
(n=136)\end{array}$ \\
\hline Total number of pregnancies & 1142 & 342 \\
\hline Mean number of pregnancies/patient & $2 \cdot 54$ & $2 \cdot 51$ \\
\hline $\begin{array}{l}\text { Number of pregnancies ending in live birth } \\
\text { Total number of pregnancies ending in miscarriage or stillbirth }\end{array}$ & $\begin{array}{c}924 \\
196(17 \%) \\
\text { of which } 152(13 \%) \\
\text { occurred during first } \\
\text { trimester }\end{array}$ & $\begin{array}{c}277 \\
62(18 \%) \\
\text { of which } 45(13 \%) \\
\text { occurred during first } \\
\text { trimester }\end{array}$ \\
\hline $\begin{array}{l}\text { Number of pregnancies therapeutically terminated } \\
\text { Number of pregnancies not yet at term } \\
\text { Number of pregnancies with toxaemia }\end{array}$ & $\begin{array}{r}18(1 \cdot 58 \%) \\
4 \\
106(10 \cdot 7 \%)\end{array}$ & $\begin{array}{l}1(0 \cdot 29 \%) \\
2 \\
38(12 \cdot 8 \%)\end{array}$ \\
\hline
\end{tabular}

TABLE 4. Number of birth defects occurring in the children born to female migraine patients and the wives of male migraine patients

\begin{tabular}{lcc}
\hline & $\begin{array}{c}\text { Female } \\
\text { migraine } \\
\text { patients }\end{array}$ & $\begin{array}{c}\text { Wives of } \\
\text { male migraine } \\
\text { patients }\end{array}$ \\
\hline Total number of live births & 924 & 277 \\
Number of children said to have a birth defect & $31(3.35 \%)$ & $11(3.97 \%)$ \\
\hline
\end{tabular}

TABLE 5. List of birth defects occurring in offspring of female migraine patients and in control group

\begin{tabular}{|c|c|c|}
\hline & $\begin{array}{c}\text { Female } \\
\text { migraine patients }\end{array}$ & $\begin{array}{l}\text { Wives of male } \\
\text { migraine patients }\end{array}$ \\
\hline $\begin{array}{l}\text { Major abnormalities (Total) } \\
\text { Cardiac } \\
\text { Spina bifida and anencephaly } \\
\text { Cerebral palsy } \\
\text { Other }\end{array}$ & $\begin{array}{l}\quad 20(2 \cdot 16 \%) \\
6 \\
3 \\
2 \\
9 \\
\text { Atresia of oesophagus } \\
\text { Mental subnormality } \\
\text { 'Severely crippled' } \\
\text { Hare-lip } \\
\text { Thyroid deficiency } \\
\text { Renal abnormality } \\
\text { Riley-Day syndrome } \\
\text { Pulmonary hypoplasia } \\
\text { 'Deformed' }\end{array}$ & $\begin{array}{c}7(2 \cdot 52 \%) \\
4 \\
0 \\
1 \\
2 \\
\text { Talipes }(2) \quad .\end{array}$ \\
\hline Minor abnormalities (Total) & $\begin{array}{l}\quad 11(1 \cdot 19 \%) \\
\text { Rib cage deformity } \\
\text { Webbed toes (3) } \\
\text { Knock knees (2) } \\
\text { Double little toe } \\
\text { Hammer toes } \\
\text { Transient heart murmur } \\
\text { Inverted nipple } \\
\text { Undescended testicle }\end{array}$ & $\begin{array}{l}\qquad 4(1.44 \%) \\
\text { Bat ear } \\
\text { Pyloric stenosis } \\
\text { Undescended testicle } \\
\text { Webbed toes }\end{array}$ \\
\hline
\end{tabular}


most instances the terms used by the mother are the ones listed. Personal questioning could often elicit further details as to the exact medical nature of the complaint but frequently recollection after some years was hazy. The overall incidence of defects in the migraine group $(3.36 \%)$ is slightly but not significantly lower than in the control group (3.97\%) and if the defects are subdivided, as shown in Table 5 , into major and minor defects there is still no suggestion that the incidence is higher in the migraine group.

\section{Drug treatment in pregnancy}

Since the study was retrospective and pregnancies dated back many years it was soon obvious to the physician in charge that the patients' recollection of drug treatment was unreliable, so much so that no attempt was made to analyse the data.

\section{Discussion}

A retrospective survey involving any population inevitably entails some degree of selection. Patients given this questionnaire were chosen because they were attending the Princess Margaret Migraine Clinic for treatment of their migraine. As they were consulting a specialist centre it would be reasonable to assume their symptoms were comparatively severe. Although the Clinic is situated in London, nearly $50 \%$ of the patients who visit reside outside the greater London area. The social classes are particularly weighted in favour of the administrative and executive workers but this is the same for both groups. The proportion of women completing the questionnaire satisfactorily is high, but this is probably to be expected from a group of people who are highly motivated to answer questions about their health. The response from the control group is not quite so high but this was not unexpected as the wives of the male patients were required to post the forms. Nevertheless, the response rate is much higher than that obtained from other postal surveys (Waters, 1970).

The women in the female migraine group were not all married and it was not asked specifically if they were married when their children were born. In practice this question may well have proved difficult for the patients to answer as frequently women attended accompanied by their husbands and the reply to such a question might have revealed information they preferred to conceal. Similarly, this question was not asked of the wives of the male migraine patients.

The reported abortion and miscarriage rate $(17 \%)$ is perhaps slightly higher than might be expected but it is generally accepted that there is an underreporting of the miscarriage rate, especially amongst less health-conscious women. It is, however, remark- ably similar in both groups of women. The incidence of toxaemia in both groups is also similar. From the work by Grant (1965), who studied changes in uterine blood vessels in endometrial biopsies obtained from migrainous women, it would not have been surprising if the incidence of toxaemia had been higher in the migrainous group.

The incidence of birth defects reported is very similar in the migraine and in the control group and the pattern of the individual abnormalities (cardiac, central nervous system, cerebral palsy, etc.) concurs very well with what might be expected from the London area (Davie, Butler and Goldstein, 1972). This suggests that, despite the fact that the study was carried out retrospectively, the incidence of reporting of defects in the offspring is probably surprisingly reliable. Furthermore, the incidence of the individual defects also agrees well with what would be expected in the London area.

The attempts to elicit the drug history made it clear that women could not remember what medication they were taking many years ago and also that they used a variety of drugs. However, since the malformation rate is not higher in the migrainous group $(3.35 \%)$ compared with the control $(3.97 \%)$ or with the national average $(3.66 \%)$ it seems unlikely that the drugs used in the treatment of migraine have any significant teratogenic activity. This contrasts with studies in epileptic women where 2- to 10-fold increases in the incidence of congenital malformations in the offspring provoked further investigation and the possible incrimination of phenytoin as a potential teratogen (Annengers and Hauser, 1974).

This study was initiated by a report which suggested that ergotamine taken during the early stages of pregnancy in an attempt to procure abortion was responsible for the development of the exceedingly rare Poland anomaly (unilateral absence of the sternoclavicular head of pectoralis major and ipsilateral syndactyly) in the children (David, 1972). An editorial in the same journal (Editorial, 1972) expanded the scope of the study and implied that ergotamine derivatives might be teratogenic, even in therapeutic doses. No cases of Poland anomaly in children born to migrainous women were reported in this study, nor were any of the deformities that did occur suggestive of this condition. Since the majority of women $(70.8 \%)$ attending the Princess Margaret Migraine Clinic had used ergotamine preparations at some time for the treatment of their migraine, any teratogenicity due to the drug is likely to have shown up as an overall increase in the number of malformations. This was not observed and it appeared that migrainous women are similar to the normal population with regard to their potential to produce abnormal children. It thus seems unlikely 
that ergotamine tartrate used in the treatment of migraine represents any teratogenic hazard.

\section{Acknowledgments}

We are grateful to the late Dr E. R. Evans and to Dr R. W. Griffiths of Sandoz Ltd, London and Basel, for their help and encouragement in progressing this study, and for providing generous financial support. We should also like to thank Mrs Jean Spiers and Miss Anne Brennan for organizing the manuscript.

\section{References}

ANNENGers, J.F. \& HAuser, W.A. (1974) Do anticonvulsants have a teratogenic effect? Archives of Neurology, 31, 364.

Callaghan, N. (1968) The migraine syndrome in pregnancy. Neurology, Minneapolis, 18, 197.
Davie, R., Butler, N. \& Goldstein, H. (1972) From Birth $\frac{\widehat{Q}}{\mathrm{~d}}$ Seven. The Second Report of the National Child Development Study, p. 156. Longman, London.

DAvid, T.J. (1972) Nature and etiology of the Polan anomaly. New England Journal of Medicine, 287, 487.

Editorial (1972) Etiology of congenital defects. New England Journal of Medicine, 287, 514.

Freedman, A.P. \& MeritT, H.H. (1959) Headache: Diag nosis and Treatment. F. A. David \& Co., Philadelphia.

GRANT, E.C.G. (1965) Relation of arterioles in the endo $\mathbb{D}$

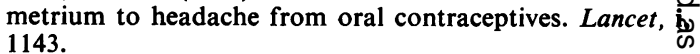

WAINSCOTT, G. (1975) A study of two thousand patients attending the Princess Margaret Migraine Clinic. In:Kopfschmerz (Ed. by G. S. Barolin, D. Saurrugg \& W Hemmer), p. 33. Otto Spatz, Munchen.

WATERS, W.E. (1970) Community studies of the prevalence of headache. Headache, 9, 178. 